\title{
Increased susceptibility to injury in older eyes
}

Jason Charng MSc, ${ }^{1}$ Christine T.O. Nguyen $P h D,{ }^{1}$ Algis J Vingrys $P h D, F A A O,{ }^{1}$ Andrew I Jobling $P h D,{ }^{2}$ Bang V Bui $P h D^{1}$

${ }^{1}$ Department of Optometry and Vision Sciences, University of Melbourne, Parkville, 3010, Victoria, Aust.

${ }^{2}$ Department of Anatomy and Neuroscience, University of Melbourne, Parkville, 3010, Victoria, Aust.

Correspondence:

Dr. Bang V. Bui

Department of Optometry and Vision Science

University of Melbourne, Parkville, 3010, Victoria, Aust

Ph: +61383447006

Fx: +61390359905

Email: bvb@unimelb.edu.au

Running title: $\quad$ Retinal susceptibility to repeated insult in young and old rat

Key words: $\quad$ ageing, electroretinogram, rat, intraocular pressure,

Number of pages: $\quad 14$

Number of words: $\quad$ total, 3262 ; abstract, 205; introduction, 354; methods, 889; results, 794; discussion, 859; conclusion, 112

Number of figures: $\quad 3$

Number of tables: $\quad 0$

Grant Support: $\quad$ NHMRC project grant 537077

Date of submission: $20^{\text {th }}$ June 2012 


\section{Abstract}

3 Purpose: To determine whether there is an age-dependent susceptibility in retinal function in 4 response to repeated anterior chamber cannulation with or without intraocular pressure (IOP)

5 elevation.

7 Methods: Baseline electroretinograms (ERGs) were measured in 3- and 18-month-old Sprague-

8 Dawley rats ( $n=16$ each group). Following baseline assessment, eyes were randomly assigned to 9 undergo a 60 minute anterior chamber cannulation with IOP either left at baseline (sham, 15

$10 \mathrm{mmHg}$ ) or elevated to $60 \mathrm{mmHg}$. This was repeated three additional times with each episode

11 separated by one week. At weeks 1 to 3 dark-adapted retinal function was assessed immediately

12 prior to cannulation with final functional assessment at week 4.

14 Results: Both sham and IOP elevated eyes of older rats showed retinal dysfunction, which 15 became more pronounced with the number of repeated insults. This effect was largest for 16 responses arising from the inner retina. Repeated insult in younger eyes did not produce a 17 change in amplitude, but an increase in the sensitivity to light of photoreceptoral and bipolar cell 18 components of the ERG.

19

20 Conclusion: Repeated trauma, not IOP, produces permanent retinal dysfunction in older eyes.

21 Younger eyes appear to be able to withstand this type of injury by upregulating sensitivity of outer 22 and middle retinal responses to maintain normal inner retinal function. 


\section{Introduction}

2 The incidence and prevalence of glaucoma increases exponentially with age. ${ }^{1}$ However, the most

3 well defined risk factor for glaucoma, elevated intraocular pressure (IOP) shows only a modest

4 increase with age. ${ }^{2}$ This suggests ageing influences IOP-independent pathways to increase the

5 risk of neuronal injury. Studies in the area of stroke provide evidence that older brains are less

6 capable of recovery from ischemic insult than younger ones. ${ }^{3,4}$ DiNapoli and colleagues ${ }^{5}$ have

7 shown that older rats exhibit a deterioration in the blood-brain-barrier, which they propose could

8 account for the greater neuronal damage and slower recovery of older brains following stroke.

10 Consistent with these studies, Kawai et $\mathrm{al}^{6}$ have shown that there is an age-related decline in 11 retinal ganglion cell (RGC) numbers (2 month versus 24 month Fischer rats). They demonstrated

12 that the remaining RGCs in 2 year old rats were more sensitive to ischemia reperfusion injury

13 induced by IOP elevation than the 2-month-old rats. Katano and colleagues ${ }^{7}$ considered the effect

14 of a short period of acute IOP elevation on retinal function in young and old Wistar rats and found

15 that 18 -month-old rats failed to fully recover from an IOP insult of $80 \mathrm{mmHg}$ for 120 minutes,

16 whereas 4-month-old rats showed complete recovery. These studies suggest that older eyes are

17 more susceptible to severe IOP elevation. What is not known is whether older eyes show

18 increased sensitivity and impaired recovery to more moderate levels of IOP elevation, and

19 whether older eyes are able to recover from repeated episodes of IOP elevation.

21 This study will investigate the susceptibility of 3 and 18-month-old rats to repeated IOP elevation

22 (60 $\mathrm{mmHg}$ for 1 hour). This combination of this IOP magnitude and duration has been shown to

23 produce the largest separation between attenuation of inner and outer retinal responses. ${ }^{8}$ Data

24 from Zhi et $\mathrm{al}^{9}$ suggest that inner retinal blood flow is compromised at $60 \mathrm{mmHg}$, but choroidal

25 flow is not, which may account for the observations of Bui et al. ${ }^{8}$. Retinal function in young rats

26 can completely recover from one episode of IOP elevation as high as $70 \mathrm{mmHg}^{10,11}$ but it is

27 unclear whether multiple episodes of a similar magnitude will produce a cumulative retinal

28 dysfunction. Given that studies have demonstrated that older neurons are more susceptible to 
1 stress, we will investigate whether repeated episodes of IOP challenge produces greater

2 functional deficits in older eyes.

4 Methods

$5 \quad$ Animals

6 All experimental procedures abide by the ARVO Statement for the Use of Animals in Ophthalmic 7 and Vision Research and approval was obtained from our facility's Animal Ethics Committee.

8 Two cohorts of Sprague-Dawley (SD) rats (three-month-old, $\mathrm{n}=16$ and eighteen-month-old, $\mathrm{n}=$

9 16) were housed in a $12: 12 \mathrm{hr}$ light:dark cycle with a maximum illuminance of 50 lux. Food and 10 water were available ad libitum.

12 Prior to experimentation, animals were anaesthetized via intramuscular injection of 13 ketamine:xylazine (60:5 mg/kg, Troy Laboratories Pty Ltd., NSW, Australia) followed by topical 14 application of proxymetacaine $(0.5 \%$, Alcon Laboratories, NSW, Australia) for corneal 15 anaesthesia. Mydriasis was achieved by application of tropicamide ( $0.5 \%$, Alcon Laboratories)

16 and phenylephrine hydrochloride (2.5\%, Chauvin Pharmaceuticals Ltd, UK). Repeated 17 cannulation appeared to have little effect on pupil size in 3 or 18-month old rats.

\section{Experimental protocol}

20 All animals underwent overnight dark adaptation to allow for ERG measurement (see later), 21 immediately after which animals underwent anterior chamber cannulation. This was repeated for 22 the next three weeks for a total of four insults, with 7 days of recovery between each IOP 23 challenge. At the fifth week only dark-adapted ERG was measured, followed by animal 24 termination. Thus, each functional assessment allowed 7 days recovery after the previous IOP 25 challenge. Repeated cannulation appeared to have little effect on pupil size in 3 or 18-month old 26 rats. 
1 Each animal had one eye randomly assigned to either IOP elevation (60 $\mathrm{mmHg}$ ) or sham (15

$2 \mathrm{mmHg}$ ) for one hour. Throughout the treatment body temperature was maintained by a circulating

3 water pad. Core temperature and pulse were monitored continuously, and blood pressure was

4 measured every 15 minutes (tail cuff sphygmomanometer; ML 125, ADInstruments Pty Ltd. NSW,

5 Australia).

7 Repeated IOP elevations

8 IOP elevation was achieved by cannulating the anterior chamber using beveled glass pipettes (75

$9 \mu \mathrm{m}$ tip, Harvard apparatus, Kent, U.K.). We have previously calibrated our glass pipettes and

10 shown that resistance across the tipis likely to have negligible effect at $60 \mathrm{mmHg} \cdot{ }^{12}$ Each glass

11 pipette was attached via polyethylene tubing $(1.27 \times 0.97 \mathrm{~mm}$, Microtube Extrusions, NSW,

12 Australia) to a Hanks balanced salt solution reservoir (JRH Biosciences, Kansas City, KS). A

13 pressure transducer was placed in series to continuously monitor IOP (Transpac, Abbot Critical

14 Care Systems, Sligo, Ireland). The height of the reservoir was pre-calibrated to give a pressure of

15 either 15 (sham baseline) or $60 \mathrm{mmHg}$ (IOP challenge). The beveled glass pipette was then

16 inserted with the aid of micromanipulators (World Precision Instruments, KITE-R, Florida, USA)

17 into the rodent's anterior chamber, perpendicular to the corneal centre avoiding contact with iris

18 and lens.

\section{Electroretinography}

22 Retinal function was assessed with the full field ERG, following dark-adaptation (>12 hrs).

23 Electrode configuration and flash characteristics have been described previously. ${ }^{10}$ Briefly, 24 purpose-built chlorided silver electrodes were used, where the active $(0.8 \mathrm{~mm}$ diameter) was

25 positioned on the corneal apex and the ring-shaped reference placed around the sclera near the 26 equator. The ground electrode (F-E2-30 Grass Telefactor, West Warwick, RI) was inserted 27 subcutaneously into the tail. Electrical contact and corneal hydration was maintained with 28 carmellose sodium $10 \mathrm{mg} / \mathrm{mL}$ (Celluvisc, Allergan, Irvine, CA, USA). The ERG stimulus was 
1 generated by light emitting diodes (5 Watt, $5500 \mathrm{~K}$, Luxeon, Calgary, Alberta, Canada) in a

2 Ganzfeld sphere (Photometric Solutions International, Huntingdale, VIC, Aust). ERGs were

3 collected over a range of luminous energies $\left(-6.53\right.$ to $2.07 \log$ scotopic cd.s. $\left.\mathrm{m}^{-2}\right)$. Noise was

4 reduced by averaging 20 signals at the dimmest light levels and progressively fewer with

5 increasing luminous energy, whilst the interstimulus interval was lengthened from 2 to 120

6 seconds to allow total recovery between successive flashes.

8 ERG analysis

$9 \quad$ Photoreceptor response

10 The leading edge of scotopic a-wave is modeled using a delayed Gaussian equation. ${ }^{13,14}$

$11 P 3(i, t)=R m_{P 3} \cdot\left[1-\exp \left(-i \cdot S \cdot\left(t-t_{d}\right)^{2}\right)\right], \mathrm{t}>\mathrm{t}_{\mathrm{d}} \quad$ Equation 1

13 In Equation 1, the $\mathrm{P} 3(\mu \mathrm{V})$ response for a given luminous energy $\left(i, \log \left(\mathrm{cd} . \mathrm{s} . \mathrm{m}^{-2}\right)\right)$ is expressed 14 as a function of time $(t, \mathrm{~s})$, saturated amplitude $\left(R m_{P 3}\right)$ and sensitivity $\left(S, \mathrm{~m}^{2} \cdot \mathrm{cd}^{-1} \cdot \mathrm{s}^{-3}\right)$ after a brief 15 delay $\left(t_{d}, \mathrm{~s}\right)$. All parameters were optimized by minimizing the sum-of-square merit function with

16 the Solver module in Excel (Microsoft ${ }^{\mathrm{TM}}$, Redmond, WA) across an ensemble of waveforms 17 returned from the top three luminous energies $\left(1.78,1.95,2.07 \log\right.$ cd.s. $\mathrm{m}^{-2}$ ), which elicits 18 saturated a-wave amplitude. ${ }^{15}$

\section{Bipolar cell response}

21 To isolate the bipolar cell component (P2) of the ERG, the modeled P3 (Equation 1) is subtracted

22 from the raw ERG. ${ }^{16}$ The amplitude of the isolated putative P2 as a function of luminous energy is 23 modeled with a saturating hyperbolic function (Equation 2). ${ }^{17}$

$24 V(i)=V_{\max } \frac{i}{i+k}$ Equation 2

26 The P2 amplitude $(V, \mu \mathrm{V})$ is defined as a function of luminous energy $\left(i, \log c d . s . m^{-2}\right), V_{\max }(\mu \mathrm{V})$ a 27 saturated amplitude and the semi-saturation constant $\left(k, \log c d . s . m^{-2}\right)$, the inverse of which gives 
1 sensitivity $(K=1 / k)$. Using the Solver module of an Excel spreadsheet (Microsoft $\left.{ }^{\mathrm{TM}}\right) V_{\max }$ and $k$

2 were optimised to minimise the sum-of-square merit function.

$4 \quad$ Retinal ganglion cell $(R G C)$ response

5 The amplitude of the ganglion cell dominated scotopic threshold response (STR) ${ }^{8}$ is measured at

6 fixed time of $130 \mathrm{~ms}$ (positive STR, pSTR) after stimulus onset. Due to the small amplitude of

7 STR components, data were averaged across three luminous energies ( $-5.33,-5.14$ and $-5.00 \log$ 8 cd.s. $\left.\mathrm{m}^{-2}\right)$.

\section{$10 \quad$ Data analysis and statistics}

11 Data for each eye (i.e. sham $15 \mathrm{mmHg}$ or IOP treated $60 \mathrm{mmHg}$ ), is expressed as a percentage 12 relative to its own baseline recorded immediately prior to the first cannulation. A repeated 13 measures two-way ANOVA established that there was no interaction between time (weeks, 14 nested factor) and treatment $(15 / 60 \mathrm{mmHg}$, between factor), thus data are collapsed across the 15 four weeks. Data across ages could then be compared with a repeated measures two-way 16 ANOVA (between factor age, within factor $15 / 60 \mathrm{mmHg}$ ). A separate two-way ANOVA was used 17 to compare treatment effect across ERG parameters within an age group (between factor ERG 18 parameters, within factor $15 / 60 \mathrm{mmHg}$ ).

\section{Results}

21 Figures $1 \mathrm{~A}$ and $\mathrm{C}$ show that 4 repeated treatments (either 15 or $60 \mathrm{mmHg}$ ) produce minimal

22 functional change in 3-month-old rats. After four episodes of cannulation the 18 month rats show

23 a reduction in the b-wave (Figure 1B) and in particular the positive component of STR (Figure 1D)

24 for both sham and IOP elevated eyes.

$26 \quad$ Insert Figure 1 here 
1 Figure 2 illustrates the effect of treatment (sham and IOP elevation) by expressing ERG 2 parameters for 3 and 18-month-old rats as a percentage change relative to each eye's own

3 baseline. For the 3-month-old rats, repeated measures ANOVA reveals that there was no 4 treatment effect (sham versus IOP elevation) for photoreceptoral amplitude $\left(\mathrm{Rm}_{\mathrm{P} 3}\right.$, Figure $2 \mathrm{~A} \mathrm{~F}_{1,19}$ $5=0.02, p=0.90)$, Bipolar cell P2 amplitude $\left(V_{\max }\right.$, Figure $\left.2 \mathrm{C}_{1,19}=0.12, p=0.73\right)$, nor ganglion

6 cell amplitude (pSTR, Figure $2 \mathrm{E}$ pSTR $\mathrm{F}_{1,18}=0.01, \mathrm{p}=0.92$ ). Furthermore, there was no effect

7 across the number of cannulations $\left(R m_{P 3} F_{119}=0.85, p=0.47 ; V_{\max } F_{1,19}=1.88, p=0.14 ; p S T R\right.$ $8 \mathrm{~F}_{1,18}=2.70, \mathrm{p}=0.05$ ), indicating that repeated anterior chamber insults (cannulation and/or IOP

9 elevation) do not affect the ERG output in 3-month-old rats. In contrast, Figure 2G shows that in

10 3-month-old rats phototransduction sensitivity (S) was significantly greater in IOP elevated eyes

11 than the sham treated eyes $\left(F_{1,18}=4.58, p<0.05\right)$. This increase in sensitivity was not constant

12 across the number of cannulations $\left(F_{1,18}=16.41, p<0.0001\right)$. Analysis of raw phototransduction

13 sensitivity in 3 month-old rats shows that there was a significant increase from baseline in both

14 sham $\left(F_{4}=2.9, p=0.03\right)$ and IOP treated $\left(F_{4}=5.2 p=0.002\right)$ eyes.

16 Bipolar sensitivity (K, Figure 2I) for 3 month sham and IOP elevated eyes were both increased

17 but there was no difference between the two groups $\left(F_{1,15}=0.81, p=0.38\right)$. A significant effect

18 across the number of cannulations was also observed $\left(F_{1,15}=4.83, p<0.01\right)$, with bipolar

19 sensitivity increasing significantly from baseline after cannulations 2 to 4 .

21 In the older rats, Figure $2 \mathrm{~B}$ shows that there was a decrease in $\mathrm{Rm}_{\mathrm{P} 3}$ for both sham and IOP 22 elevated eyes across all cannulations when compared to baseline. This relative decrease was the 23 same for sham and IOP elevated groups $\left(F_{1,23}=0.31, p=0.58\right)$. However, there was a significant 24 effect across the number of cannulations $\left(F_{1,23}=7.04, p<0.001\right)$. This finding is similar for the 25 bipolar cell $V_{\max }$, which declines with the number of cannulations (Figure 2D, IOP effect $F_{1,23}=$ 26 1.12, $p=0.30$, cannulation effect $\left.F_{1,23}=20.13, p<0.0001\right)$. In Figure $2 F$, there was also no 27 difference between IOP elevated and sham eyes $\left(F_{1,21}=0.02, p=0.90\right)$, however the pSTR did 28 decline significantly after the first cannulation $\left(F_{1,21}=6.99, p<0.001\right)$. 
2 Unlike the improvement in sensitivity seen in 3-month-old rats, photoreceptor sensitivity in older

3 rats (Figure $2 \mathrm{H}$ ) decreases after the fourth repeated cannulation $\left(F_{1,21}=3.23, p<0.05\right)$ in both

4 sham and IOP treated cohorts $\left(F_{1,21}=0.15, p=0.71\right)$. Bipolar cell sensitivity ( $K$, Figure $\left.2 \mathrm{~J}\right)$ in older

5 rats also show a significant decline with repeated cannulation $\left(F_{1,21}=12.89, p<0.0001\right)$ for both

6 sham and IOP elevated eyes $\left(F_{1,21}=0.01, p=0.94\right)$.

Insert Figure 2 here

10 Figure 3 shows the overall effect of repeated injury by averaging across the four cannulations.

11 Two-way ANOVA between age group and treatments revealed a significant age effect for all ERG

12 parameters $\left(R_{\mathrm{P}} \mathrm{F}_{1,1}=6.02, \mathrm{p}<0.05 ; \mathrm{V}_{\max } \mathrm{F}_{1,1}=3.05, \mathrm{p}<0.0001 ; \mathrm{pSTR} \mathrm{F}_{1,1}=12.03, \mathrm{p}<0.01\right.$;

$\left.13 S F_{1,1}=8.80, p<0.01 ; K_{1,1}=47.62, p<0.0001\right)$. There was no IOP elevation effect in either 3

14 or 18-month-old rats $\left(R m_{P 3} F_{1,1}=0.09, p=0.76 ; V_{\max } F_{1,1}=0.50, p=0.48 ; p S T R F_{1,1}=0.27, p=\right.$

$\left.15 \quad 0.61 ; S F_{1,1}=0.47, p=0.49 ; K F_{1,1}=0.20, p=0.65\right)$.

17 To investigate whether an ERG component amplitude was more affected than others, a two-way

18 ANOVA comparing relative changes in $\mathrm{Rm}_{\mathrm{P} 3}, \mathrm{~V}_{\max }$ and pSTR across sham and IOP treated eyes

19 was performed for both ages. In the 3-month-old rats, there was no significant difference between

20 ERG components $\left(F_{1,2}=1.31, p=0.28\right)$. However, the decrease in amplitude across $R_{\mathrm{P} 3}, \mathrm{~V}_{\max }$

21 and pSTR was not uniform in the older rats $\left(F_{1,2}=15.16, p<0.0001\right)$, as a Bonferroni post-hoc

22 test reveals that the ganglion cell dominated PSTR was significantly more attenuated than the 23 photoreceptoral $\mathrm{Rm}_{\mathrm{P} 3}$.

25 In 3-month-old rats bipolar cell sensitivity showed a larger increase with repeated cannulation 26 than did photoreceptoral sensitivity $\left(F_{1,1}=12.00, p<0.01\right.$, comparison across Figures 3D and 27 3E). In contrast, older rats showed a greater reduction in bipolar cell sensitivity when compared 
1 with the photoreceptoral sensitivity $\left(F_{1,1}=106.00, p<0.0001\right.$, comparison across Figures 3D and

$23 \mathrm{E})$

\section{Discussion}

7 This study shows that repeated injury has little effect on the retinal function of three-month-old

8 albino rats, but produces dysfunction in eighteen-month-old rats. The observation that there was

9 no dysfunction in younger animals is consistent with previous findings that younger rats can

10 completely recover from a single episode of IOP challenge similar in magnitude to that employed

11 here $\left(70 \mathrm{mmHg}\right.$ for 1 hour). ${ }^{10,11,18}$ Our study extends previous reports, to show that younger rats

12 are able to resist repeated moderate IOP insults of short duration separated by one week.

14 Our data provides a possible explanation for the functional resilience of the inner retina in 3-

15 month-old rats. In particular, ganglion cell dysfunction arising from repeated injury could be

16 masked if the upstream input to the ganglion cells were to be increased. One way greater input

17 could be achieved is via an improvement in photoreceptor and/or bipolar cell sensitivity to light, as

18 is observed in our data (Figure 2). This means that, at dim light levels, the same number of

19 photons captured would produce a larger ganglion cell response (leftward shift of the luminance

20 energy response function). The mechanism underlying this observed improvement in sensitivity

21 arises is unclear. Studies in the brain show that new neurons can proliferate at the site of

22 ischemic injury. ${ }^{19}$ However, an increase in the number of photoreceptors should produce larger

23 photoreceptoral amplitude without a change in sensitivity, which was not the case in our data.

24 Therefore the upregulation of sensitivity in 3-month-old rats reflect other mechanisms, possibly

25 alterations in the efficiency of phototransduction proteins. ${ }^{20}$ 
1 Our data also show that in 3-month-old rats bipolar cell sensitivity $\left(52.8 \pm 16.3 \%, F_{1,1}=12.00, p<\right.$

$20.01)$ increased even more than phototransduction sensitivity $(14.0 \pm 4.0 \%)$. This is consistent

3 with the suggestion of Aleman et $\mathrm{al}^{21}$ that rod-bipolar cell synapses can increase following retinal

4 injury. A consequence of a greater number of bipolar cell dendrites with the same number of 5 photoreceptors (same phototransduction amplitude) would be increased convergence, which

6 could manifest as an improved sensitivity to light in the rod pathway. We propose that 7 upregulation of sensitivity within the phototransduction cascade and between the photoreceptor 8 and bipolar cell synapses in 3-month-old rats reflect a compensatory mechanism to maintain 9 normal retinal output in response to repeated injury. The data from 18-month-old rats suggests 10 that such compensatory mechanisms are insufficient. Our previous study ${ }^{22}$ showed that aging 11 itself in 18-month-old compared with 3-month-old rats causes increased sensitivity. This is 12 consistent with a previous study report that in older mice there is evidence of proliferation of rod 13 bipolar and horizontal cell dendrites towards rod photoreceptor spherules. ${ }^{23}$ It is possible that 1814 month-old rats have already reached their maximal capacity to increase sensitivity and hence in 15 response to repeated stress cannot further compensate. This manifests as loss in ganglion cell 16 output with repeated insult in the older cohort.

18 It is important to note that in the older eyes both repeated sham cannulation and IOP elevation 19 produced similar functional deficits. Based on this observation, we believe that there is a common 20 mechanism of injury in both sham and IOP elevated eyes. While the exact mechanism of injury in 21 the older eyes from cannulation is unclear, based on previous reports we speculate inflammation 22 may be involved. Hoyng et $\mathrm{al}^{24}$ have reported that cannulation of the rabbit anterior chamber 23 resulted in classic signs of inflammation, which were observable on the anterior ocular surface as 24 well as in the aqueous humour. More recently, Chinnery et $\mathrm{al}^{25}$ showed that corneal trauma 25 followed by topical application of a lipopolysaccharide in mice produced retinal inflammation. It is 26 also well established that basal inflammation increases with age $\mathrm{e}^{26-28}$ as demonstrated by 27 accumulations of macrophages ${ }^{29}$ and microglia $^{25}$ in subretinal space of older mice. Thus it is 
1 possible that inflammatory processes contribute to the non-specific functional losses arising from

2 repeated insults to older eyes.

\section{Conclusion}

5 In 3 month animals, four repeated cannulations with or without IOP elevation did not decrease the

6 amplitude of retinal responses. There was a significant improvement in the sensitivity of outer

7 retinal components, which we believe represents a compensatory mechanism to account for the

8 lack of inner retinal dysfunction in 3-month-old rats. In older eyes repeated trauma (both sham

9 treatment and IOP elevation) produced a cumulative loss of retinal function with the number of

10 cannulations, with the exact mechanism for injury unknown. However, we propose that as the

11 older eyes have already upregulated retinal sensitivity to counteract age-related cell loss, there is

12 no longer a buffer to protect against additional injury.

\section{Acknowledgements}

15 This work was supported by NHMRC project grant 537077. This manuscript has been presented

16 as a poster at The Association for Research in Vision and Ophthalmology 2012; Vingrys AJ,

17 Charng J, Nguyen CT, Jobling Al, Bui BV. The effect of repeated intracameral injection on young

18 and old rat eyes. Invest Ophthalmol Vis Sci. ARVO E-Abstract 2012. Florida, USA.

\section{References} 21 1. Quigley HA. Number of people with glaucoma worldwide. Br J Ophthalmol 1996;80:3892293.

23 2. Coleman AL, Miglior S. Risk factors for glaucoma onset and progression. Surv 24 Ophthalmol 2008;53 Suppl1:S3-10.

253 3. Popa-Wagner A, Buga AM, Kokaia Z. Perturbed cellular response to brain injury during 26 aging. Ageing Res Rev 2009.

27 4. Badan I, Buchhold B, Hamm A, Gratz M, Walker LC, Platt D, Kessler C, Popa-Wagner A. 28 Accelerated glial reactivity to stroke in aged rats correlates with reduced functional recovery. $J$ 29 Cereb Blood Flow Metab 2003;23:845-54.

$30 \quad 5 . \quad$ DiNapoli VA, Huber JD, Houser K, Li X, Rosen CL. Early disruptions of the blood-brain 31 barrier may contribute to exacerbated neuronal damage and prolonged functional recovery 32 following stroke in aged rats. Neurobiol Aging 2008;29:753-64. 
1

2

3

4

6. Kawai SI, Vora S, Das S, Gachie E, Becker B, Neufeld AH. Modeling of risk factors for the degeneration of retinal ganglion cells after ischemia/reperfusion in rats: effects of age, caloric restriction, diabetes, pigmentation, and glaucoma. FASEB J 2001;15:1285-7.

7. Katano H, Ishihara M, Shiraishi Y, Kawai Y. Effects of aging on the electroretinogram during ischemia-reperfusion in rats. Jpn J Physiol 2001;51:89-97.

8. Bui BV, Fortune B. Ganglion cell contributions to the rat full-field electroretinogram. J Physiol 2004;555:153-73.

9. Zhi Z, Cepurna WO, Johnson EC, Morrison JC, Wang RK. Impact of intraocular pressure on changes of blood flow in the retina, choroid, and optic nerve head in rats investigated by optical microangiography. Biomed Opt Express 2012;3:2220-33.

10. He Z, Bui BV, Vingrys AJ. The rate of functional recovery from acute IOP elevation. Invest Ophthalmol Vis Sci 2006;47:4872-80.

11. He Z, Bui BV, Vingrys AJ. Effect of Repeated IOP Challenge on Rat Retinal Function. Invest Ophthalmol Vis Sci 2008.

12. Kong YX, Crowston JG, Vingrys AJ, Trounce IA, Bui VB. Functional changes in the retina during and after acute intraocular pressure elevation in mice. Invest Ophthalmol Vis Sci 2009;50:5732-40.

13. Hood DC, Birch DG. Rod phototransduction in retinitis pigmentosa: estimation and interpretation of parameters derived from the rod a-wave. Invest Ophthalmol Vis Sci 1994;35:2948-61.

14. Lamb TD, Pugh EN, Jr. A quantitative account of the activation steps involved in phototransduction in amphibian photoreceptors. J Physiol 1992;449:719-58.

15. Dang TM, Tsai TI, Vingrys AJ, Bui BV. Post-receptoral contributions to the rat scotopic electroretinogram a-wave. Doc Ophthalmol 2011;122:149-56.

16. Hood DC, Birch DG. A computational model of the amplitude and implicit time of the bwave of the human ERG. Vis Neurosci 1992;8:107-26.

17. Fulton $\mathrm{AB}$, Rushton WA. The human rod ERG: correlation with psychophysical responses in light and dark adaptation. Vision Res 1978;18:793-800.

18. He Z. Functional consequences of acute IOP challenge. Melbourne: The University of Melbourne; 2006.

19. Bingham B, Liu D, Wood A, Cho S. Ischemia-stimulated neurogenesis is regulated by proliferation, migration, differentiation and caspase activation of hippocampal precursor cells. Brain Res 2005;1058:167-77.

20. Pugh EN, Jr., Lamb TD. Phototransduction in Vertebrate Rods and Cones: Molecular Mechanisms of Amplification, Recovery and Light Adaptation. In: Handbook of Biological Physics: Elsevier Science B.V., 2000.

21. Aleman TS, LaVail MM, Montemayor R, Ying G, Maguire MM, Laties AM, Jacobson SG, Cideciyan AV. Augmented rod bipolar cell function in partial receptor loss: an ERG study in P23H rhodopsin transgenic and aging normal rats. Vision Res 2001;41:2779-97.

22. Charng J, Nguyen CT, Bui BV, Vingrys AJ. Age-related retinal function changes in albino and pigmented rats. Invest Ophthalmol Vis Sci 2011;52:8891-9.

23. Liets LC, Eliasieh K, van der List DA, Chalupa LM. Dendrites of rod bipolar cells sprout in normal aging retina. Proc Natl Acad Sci U S A 2006;103:12156-60.

24. Hoyng PF, Verbey N, Thorig L, van Haeringen NJ. Topical prostaglandins inhibit traumainduced inflammation in the rabbit eye. Invest Ophthalmol Vis Sci 1986;27:1217-25.

25. Chinnery HR, McLenachan S, Binz N, Sun Y, Forrester JV, Degli-Esposti MA, Pearlman E, McMenamin PG. TLR9 Ligand CpG-ODN Applied to the Injured Mouse Cornea Elicits Retinal Inflammation. Am J Pathol 2011.

26. Cartier A, Cote M, Lemieux I, Perusse L, Tremblay A, Bouchard C, Despres JP. Agerelated differences in inflammatory markers in men: contribution of visceral adiposity. Metabolism 2009;58:1452-8.

27. Gurven M, Kaplan H, Winking J, Finch C, Crimmins EM. Aging and inflammation in two epidemiological worlds. J Gerontol A Biol Sci Med Sci 2008;63:196-9.

28. Hamer M, Chida $\mathrm{Y}$, Stamatakis E. Utility of C-reactive protein for cardiovascular risk stratification across three age groups in subjects without existing cardiovascular diseases. Am J Cardiol 2009;104:538-42. 
1 29. Luhmann UF, Robbie S, Munro PM, Barker SE, Duran Y, Luong V, Fitzke FW, 2 Bainbridge JW, Ali RR, MacLaren RE. The drusenlike phenotype in aging Ccl2-knockout mice is 3 caused by an accelerated accumulation of swollen autofluorescent subretinal macrophages. 4 Invest Ophthalmol Vis Sci 2009;50:5934-43. 


\section{$1 \quad$ Figure Legends}

2 Figure 1: Panel A shows group average dark-adapted responses in 3-month-old rats after four

3 sham (dashed) or IOP elevations (solid line). The grey line shows ERG response recorded at

4 baseline. Panel B shows group average dark-adapted responses in 18-month-old rats, other

5 details as per Panel A. Panel $\mathbf{C}$ shows group average scotopic threshold responses in 3 month

6 rats, other details as per Panel A. Panel D shows group average scotopic threshold responses in

718 month rats, other details as per Panel A.

9 Figure 2: Effect of repeated sham (unfilled circles) or IOP elevation (filled circles) on retinal

10 function in 3 and 18-month-old rats. All data are expressed as a change relative to baseline

11 (average \pm SEM). ERG parameters from 3-month-old rats are shown in Panels $\mathbf{A}\left(\mathrm{Rm}_{\mathrm{P} 3}\right.$,

12 phototransduction amplitude), C ( $\mathrm{V}_{\max }$, bipolar cell $\mathrm{P} 2$ amplitude), E (pSTR, ganglion cell

13 amplitude), G (S, phototransduction sensitivity) and I ( $\mathrm{K}$, bipolar cell sensitivity). ERG parameters

14 from older eyes are shown in Panels $\mathbf{B}\left(\mathrm{Rm}_{\mathrm{P} 3}\right), \mathbf{D}\left(\mathrm{V}_{\max }\right), \mathbf{F}(\mathrm{pSTR}), \mathbf{H}(\mathrm{S})$ and $\mathbf{J}(\mathrm{K})$.

16 Figure 3: Average effect of repeated sham (unfilled) versus repeated IOP (filled) in 3 and 18-

17 month-old rats. All data expressed as a change relative to baseline (average \pm SEM) across all

18 time points. ERG parameters shown in panels $\mathbf{A}\left(\mathrm{Rm}_{\mathrm{P} 3}\right), \mathbf{B}\left(\mathrm{V}_{\max }\right), \mathbf{C}(\mathrm{pSTR}), \mathbf{D}(\mathrm{S}), \mathbf{E}(\mathrm{K})$. 


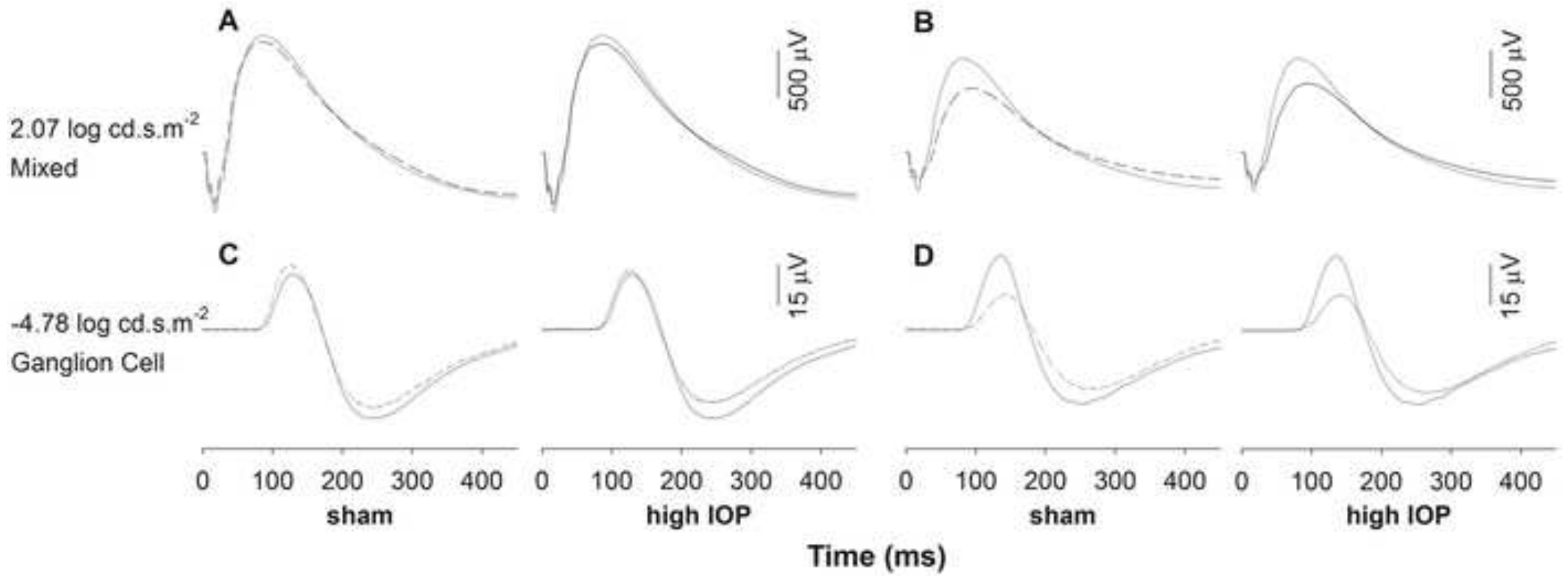




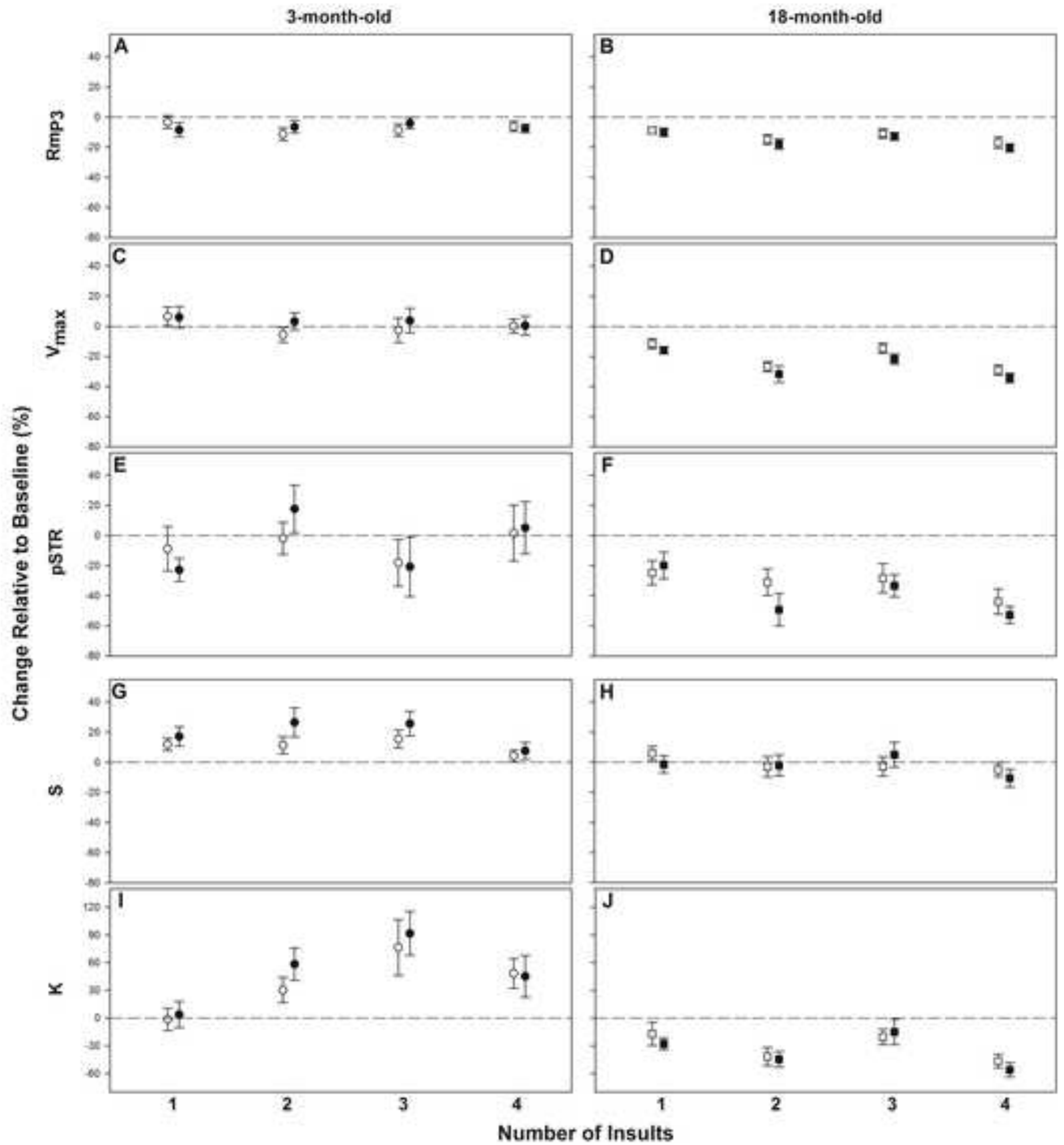




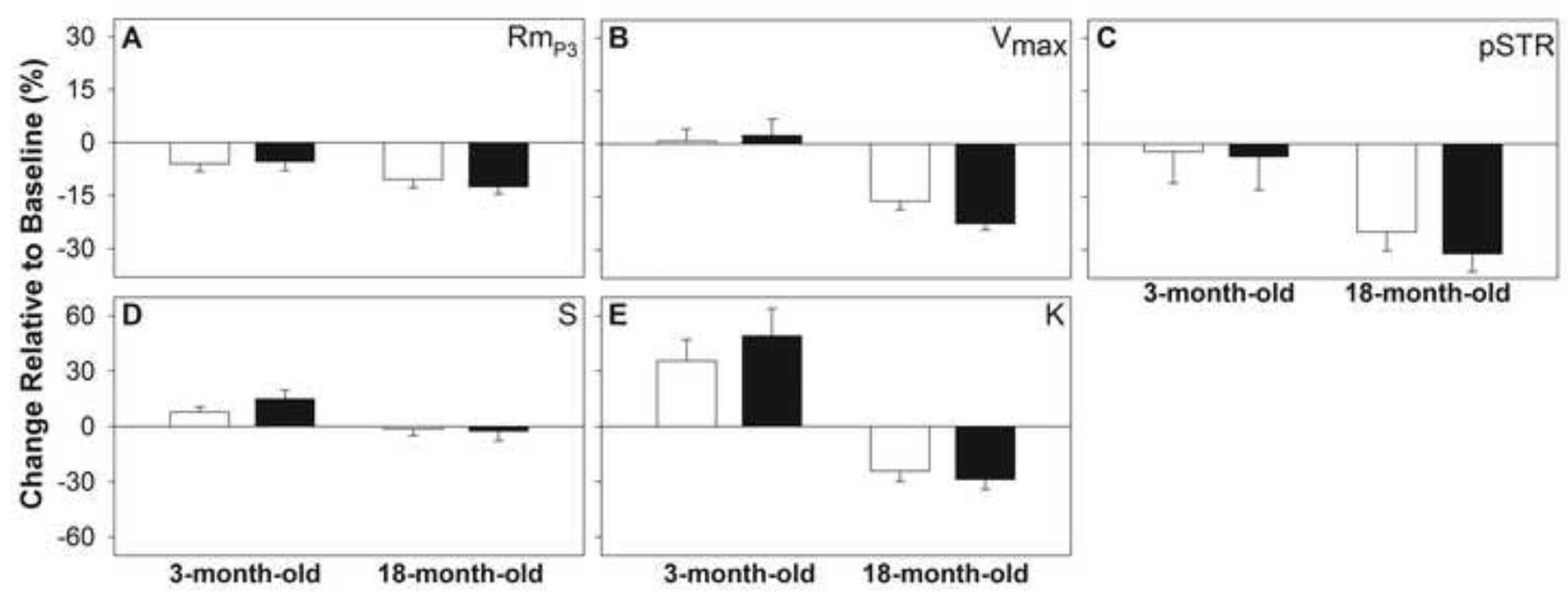




\section{University Library}

- MINERVA A gateway to Melbourne's research publications

Minerva Access is the Institutional Repository of The University of Melbourne

Author/s:

Charng, Jason; Nguyen, Christine T. O.; Vingrys, Algis J.; Jobling, Andrew I.; Bui, Bang V.

Title:

Increased susceptibility to injury in older eyes

Date:

2013

Citation:

Charng, J., Nguyen, C. T. O., Vingrys, A. J., Jobling, A. I. \& Bui, B. V. (2013). Increased susceptibility to injury in older eyes. Optometry and Vision Science, 90(3), 275-281.

Persistent Link:

http://hdl.handle.net/11343/39700

File Description:

Increased susceptibility to injury in older eyes 


\section{University Library}

\section{- M M N E R VA A gateway to Melbourne's research publications}

Minerva Access is the Institutional Repository of The University of Melbourne

Author/s:

Charng, J;Nguyen, CTO;Vingrys, AJ;Jobling, Al;Bui, BV

Title:

Increased Susceptibility to Injury in Older Eyes

Date:

2013-03-01

Citation:

Charng, J., Nguyen, C. T. O., Vingrys, A. J., Jobling, A. I. \& Bui, B. V. (2013). Increased Susceptibility to Injury in Older Eyes. OPTOMETRY AND VISION SCIENCE, 90 (3), pp.275-281. https://doi.org/10.1097/OPX.0b013e3182826025.

Persistent Link:

http://hdl.handle.net/11343/32956 